\title{
Riqueza de espécies e distribuição espacial e temporal em comunidade de anuros (Amphibia, Anura) em uma localidade de Tijucas do Sul, Paraná, Brasil
}

\author{
Carlos E. Conte ${ }^{1} \&$ Reginaldo A. Machado ${ }^{2}$ \\ ${ }^{1}$ Mülleriana: Sociedade Fritz Müller de Ciências Naturais. Caixa Postal 19093, 81531-980 Curitiba, Paraná, Brasil. \\ E-mail: kadu_conte@yahoo.com.br \\ 2 Faculdade de Ciências Biomédicas de Cacoal. Avenida Cuiabá 3087, Jardim Clodoaldo, 78976-005 Cacoal, Rondônia, \\ Brasil.E-mail: anurans@uol.com.br
}

\begin{abstract}
Species richness and spatial and temporal distributions of the anuran (Amphibia, Anura) community in a locality of Tijucas do Sul, Paraná, Brazil. In this study we have improved ecological data on the anuran fauna of Lagoa $\left(25^{\circ} 55^{\prime} \mathrm{S}, 49^{\circ} 11^{\prime} \mathrm{W}\right)$, located in the Municipality of Tijucas do Sul, State of Paraná, Brazil. The local vegetation is composed by pieces of disturbed Araucaria forest, anthropic managed pine forest, and few areas with agricultural occupations. During 13 months, from March 2000 to March 2001, spatial and temporal distributions data of anurans species were collected; informations about the microhabitat use and vocalization site were also obtained. Twenty-three species were registered. No anuran called during the most dry months (April and May), but in the statistical analysis this activity was more correlated to temperature than to the rainfall. Few spatial overlap among the species on the vocalization sites was observed, as these species use different call sites.

KEY WORDS. Anuran ecology, biorhythm, communities organization, habitat.
\end{abstract}

RESUMO. O presente trabalho teve como objetivo fornecer dados ecológicos sobre a anurofauna da localidade de Lagoa $\left(25^{\circ} 55^{\prime} \mathrm{S}, 4^{\circ} 11^{\prime} \mathrm{W}\right)$, Município de Tijucas do Sul, Paraná, Brasil. Dentro da área de estudo a vegetação é expressa por diminutos relictos de Floresta Ombrófila Mista primária alterada e formações antrópicas, sobretudo áreas de reflorestamento com Pinus sp. e pequenas áreas de terra ocupadas pela agricultura. Durante os meses de março de 2000 a março de 2001 , foram coligidos dados sobre a distribuição espacial e temporal das espécies, bem como informações quanto à utilização do ambiente como sítio de vocalização. Foram registradas 23 espécies de anfíbios anuros. Nenhum anfíbio foi encontrado vocalizando durante os meses mais secos (abril e maio), porém pela análise estatística a atividade de vocalização esteve mais correlacionada com a temperatura do que com a pluviosidade. Quase não houve sobreposição espacial entre as espécies nos sítios de vocalização, visto que as mesmas utilizam sítios de vocalização diferentes.

PALAVRAS CHAVE. Biorritmo, ecologia de anuros, habitat, organização de comunidades.

O estudo da distribuição temporal e espacial dos organismos é fundamental para o entendimento de muitos de seus processos de inter-relação com o ambiente (BREwer 1994). Esses mecanismos, relacionados com a estrutura física do canto, permitem a coexistência de anuros agregados no período reprodutivo em um mesmo habitat (CARdoso et al. 1989, Cardoso \& Velliard 1990).

Embora durante essa associação possam ocorrer interações interespecíficas, a tolerância diferenciada à temperatura e à chuva determina variações nos períodos de atividade, segregando os anuros sazonalmente (Duellman \& Trueb 1986). Já a segregação espacial no grupo envolve a utilização distinta de habitats e sítios de vocalização para atividade de vocalização e desova, estando intimamente relacionada aos modos reprodutivos das espécies (Duellman \& Trueb 1986).

Abordagens sobre esse tema em comunidades de anuros no Brasil estão, de forma geral, concentradas na região Sudeste (CArdoso et al. 1989, Heyer et al. 1990, Rossa-Feres \& Jim 1994, Pombal JR. 1997, Bertoluci 1998, Bertoluci \& Rodrigues 2002), sendo a maioria relacionadas aos sítios de vocalização, habitats de reprodução, período reprodutivo e turnos de vocalização.

Para o sul do Brasil, em particular para o Estado do Paraná, a anurofauna é pouco conhecida, o que faz ainda freqüente a ocorrência de novos registros (BERNARDE 1998, 1999, LingNaU 2000, Machado \& Conte 2001, Machado \& Haddad 2001, Conte et al. 2005) ou mesmo a descoberta de novas espécies (LANGONE \& Segalla 1996, Pombal Jr. et al. 1998, Castanho \& Haddad 2000, Ribeiro et al. 2005). Por outro lado, há uma carência efetiva de informações biológicas para as comunidades, sejam estas em quais níveis forem, na maioria das regiões paranaenses (MACHADo et al. 1999), uma realidade que dificulta a tomada de decisões quanto à conservação das espécies e de seus habitats.

Revista Brasileira de Zoologia 22 (4): 940-948, dezembro 2005 
Tal realidade é agravada, uma vez que a cobertura florestal do Estado do Paraná que perfazia quase $85 \%$ de seu território, hoje está reduzida a menos de 4\% (Sos Mata AtLÂnTica 1998). Seguramente, a maior ameaça aos anuros nesse Estado é a perda de habitats, sendo impossível saber com precisão quantas espécies podem ter sido extintas ou estarem sob algum grau de ameaça.

Devido a esses fatores e, aliado à importância ecológica dos anfíbios, o presente estudo tem como objetivo verificar a utilização dos recursos espacial e temporal em habitats com diferentes graus de conservação, bem como inventariar uma região nunca antes estudada, em área de Floresta Ombrófila Mista, no Município de Tijucas do Sul, Paraná, Brasil.

\section{MATERIAL E MÉTODOS}

\section{Área de estudo}

O estudo foi desenvolvido no Município de Tijucas do Sul ( $\left.25^{\circ} 45^{\prime} \mathrm{S}, 49^{\circ} 11^{\prime} \mathrm{W}\right)$, localizado na porção sul do Primeiro Planalto Paranaense, a $60 \mathrm{~km}$ de Curitiba. A altitude local varia entre 850 e $1350 \mathrm{~m}$, sendo geomorfologicamente originada do mesmo sistema estrutural da Serra do Mar (MAACK 1981). O clima é o subtropical úmido mesotérmico ou Cfb de Köppen, com verões frescos e ocorrência de geadas severas e freqüentes, com médias de temperatura mais quente inferior a $22^{\circ} \mathrm{C}$ e a dos meses mais frios é inferior a $18^{\circ} \mathrm{C}$ (FerReIra 1996). A precipitação anual média é de $1400 \mathrm{~mm}$, com concentração de chuvas no período de outubro a março, sem uma estação seca definida (PARANÁ 1987).

As associações vegetacionais se enquadram, em sua maioria, nos domínios da Floresta Ombrófila Mista (Veloso et al. 1991), em suas formações Montana e Aluvial. A maior parte da vegetação encontra-se bastante alterada em função da agricultura intensiva e da exploração madeireira (A. Koehler, com. pess.). Assim, dentro da área de estudo a vegetação constitui-se de um mosaico de relictos primários, formações secundárias em diferentes estádios de regeneração e formações antrópicas, sobretudo reflorestamento de Pinus spp. e Eucalyptus spp.

Para este estudo foram selecionados três habitats categorizados da seguinte forma:

Área A1 - interior de floresta (255 $\left.7^{\prime} 06^{\prime \prime} \mathrm{S}, 4^{\circ} 13^{\prime} 14^{\prime \prime} \mathrm{W}\right)$ : ribeirão com cerca de $3 \mathrm{~m}$ de comprimento por $1 \mathrm{~m}$ de largura, que desemboca em um brejo ( $2 \mathrm{~m} \mathrm{X} 3 \mathrm{~m}$ ). Possui em seu entorno uma densa formação herbácea, arbustiva e arbórea. Localizado em um fragmento florestal alterado de aproximadamente seis hectares, que mantém preservado o perfil característico de floresta de Araucária (Liebsch \& ACra 2004).

Área A2 - borda florestal (25 $\left.57^{\prime} 13^{\prime \prime} \mathrm{S}, 49^{\circ} 13^{\prime} 16^{\prime \prime} \mathrm{W}\right)$ : açude parcialmente circundado por floresta, com cerca de $150 \mathrm{~m}$ em seu maior comprimento e $30 \mathrm{~m}$ em sua maior largura. Possui vários taboais (Typha sp.). Uma margem é circundada pelo fragmento florestal da Área A1; na outra margem possui um gramado com grande quantidade de árvores, porém sem sub-bosque.

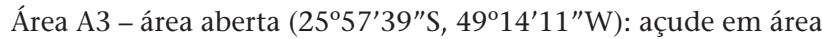
aberta $(45 \times 20 \mathrm{~m})$ de propriedade particular que fica a $3 \mathrm{~km}$ de distância das demais áreas. Em uma margem encontram- se poucas árvores de pequeno porte e uma pocilga com escoamento de dejetos diretamente no açude. Na outra margem há uma pequena área de capoeirão (7 x 3 m), sendo o restante circundado por plantação de fumo (Nicotiana tabacum Linnaeus).

As áreas A1 e A2 estão dentro da área-sede do Programa de Ação Comunitária e Ambiental da Pontifícia Universidade Católica do Paraná (ProAÇão-PucPr).

\section{Coleta de dados e análises estatísticas}

Foram realizadas 13 visitas com freqüência mensal ao campo, entre março de 2000 e março de 2001, com três dias de duração, sendo um para cada habitat amostrado. As coletas foram noturnas entre 19:00 e 23:00 h, sendo anotadas as espécies em atividade de vocalização, bem como seus sítios de vocalização.

A constância de ocorrência (C) foi calculada (DAJOz 1972) e de acordo com os valores de $\mathrm{C}$, foram definidas as seguintes categorias: a) espécies comuns, presentes em mais de 50\% da amostragem; b) relativamente comuns, entre 25 a $50 \%$ e c) esporádicas, em menos de $25 \%$ da amostragem.

Para comparação da anurofauna nos habitats estudados, foi utilizado o índice de afinidade de Jaccard, com posterior análise de agrupamento ("clustering") pelo método de média não ponderada (UPGMA) (KREBS 1999). A influência da temperatura, precipitação pluviométrica e umidade relativa do ar no número de espécies em atividade de vocalização foi verificada pela aplicação do coeficiente de correlação de Spearman ( $r_{s}$ ) (ZAR 1984). Esses parâmetros foram divididos em: 1) média mensal, dos parâmetros acima citados, considerando 30 dias antes da fase de campo; e 2) média do período amostral, obtida durante a fase de campo. Os dados do regime térmico e pluviométrico da região foram cedidos pelo Instituto Tecnológico SIMEPAR, da estação climatológica Lapa $\left(25^{\circ} 78^{\prime} \mathrm{S}, 49^{\circ} 76^{\prime} \mathrm{W}\right)$.

Exemplares testemunhos foram depositados na Coleção Científica do Departamento de Zoologia e Botânica da Universidade Estadual Paulista, Campus de São José do Rio Preto (DZSJRP).

\section{RESULTADOS}

\section{Riqueza de espécies e sazonalidade}

Foram registradas 23 espécies de anfíbios anuros pertencentes a três famílias: Bufonidae (2), Leptodactylidae (8) e Hylidae (13) (Tab. I). Destas, 21 foram encontradas em atividade de vocalização (Fig. 1). O índice de constância indicou nove espécies comuns: Bufo ictericus, Physalaemus cuvieri, P. gracilis, Aplastodiscus albosignatus, A. perviridis, Dendropsophus minutus, Hypsiboas albopunctatus, $H$. bischoffi e Scinax perereca; sete espécies relativamente comuns: Bufo abei, Adenomera marmorata, Leptodactylus ocellatus, Sphaenorhynchus surdus, Dendropsophus sanborni, Hypsiboas faber e $H$. prasinus, e cinco raras: Proceratophrys boiei, Odontophrynus americanus, Bokermannohyla circumdata, Scinax berthae e $S$. squalirostris.

Em uma visita posterior ao término do estudo (05/X/ 2002), machos de Cycloramphus bolitoglossus foram encontra- 
Tabela I. Lista das espécies de anfíbios anuros registrados para o Município de Tijucas do Sul (PR) durante o período de março de 2000 a março de 2001 e habitats utilizados durante atividade de vocalização: (A1) ribeirão no interior de floresta, (A2) açude circundado por floresta, (A3) açude em área aberta, $(+)$ presença, $(-)$ ausência, ${ }^{* *}$ ) espécies que não foram encontradas em atividade de vocalização.

Famílias e Espécies

Habitats

A1 $\mathrm{A} 2 \quad \mathrm{~A} 3$

Bufonidae

Bufo abei Baldissera Jr., Caramaschi \& Haddad, 2004

Bufo ictericus Spix, 1824

Leptodactylidae

Adenomera marmorata Steindachner, 1867

Leptodactylus ocellatus (Linnaeus, 1758)

Physalaemus cuvieri Fitzinger, 1826

Physalaemus gracilis (Boulenger, 1883)

Proceratophrys boiei (Wied-Neuwied, 1825)

Odontophrynus americanus (Duméril \& Bibron, 1841)

Eleutherodactylus guentheri (Steindachner, 1864)

Cycloramphus bolitoglossus (Werner, 1897)

Hylidae

Aplastodiscus albosignatus (A. Lutz \& B. Lutz, 1938)

Aplastodiscus perviridis A. Lutz, 1950

Bokermannohyla circumdata (Cope, 1870)

Dendropsophus minutus (Peters, 1872)

Dendropsophus sanborni (Schmidt, 1944)

Hypsiboas albopunctatus (Spix, 1824)

Hypsiboas bischoffi (Boulenger, 1887)

Hypsiboas faber (Wied-Neuwied, 1821)

Hypsiboas prasinus (Burmeister, 1856)

Scinax berthae (Barrio, 1962)

Scinax perereca Pombal Jr., Haddad \& Kasahara, 1995

Scinax squalirostris (A. Lutz, 1925)

Sphaenorhynchus surdus (Cochran, 1953)

Total

A1

A3

$\begin{array}{lll}- & + & + \\ - & + & +\end{array}$

$\begin{array}{lll}+ & - & - \\ - & + & -\end{array}$

+ +

$+\quad+$

$+\quad-\quad-$

$+\quad+$

**

** ** * * * * *

dos em atividade de vocalização após chuva torrencial, no interior do fragmento florestal entremeados à serapilheira, distantes de corpos d'água.

Todas as espécies apresentaram atividade de vocalização predominantemente noturna. Entretanto, B. ictericus e $P$. gracilis também foram observadas vocalizando durante o dia, nos meses em que o maior número de machos destas espécies estavam ativos (agosto e setembro, respectivamente). Esporadicamente ao longo do estudo, $S$. perereca foi observada vocalizando à tarde, próximo ao período crepuscular, no interior de bromélias epífitas até quatro metros de altura no interior do fragmento florestal. Apesar disso, a espécie não foi observada utilizando esse tipo de vegetação durante a noite. Provavelmente iniciam a vocalização a partir dos locais de abrigo diurno, descendo dos mesmos até o sítio de vocalização no período noturno.
A maioria das espécies apresentou atividade de vocalização entre outubro 2000 e março de 2001 (Fig. 1), período de maior acúmulo de chuva e de temperatura mais elevada (Figs 2-4). Nos meses mais secos, abril e maio, não foram registradas espécies vocalizando (Fig. 2).

Não houve correlação entre o número de espécies em atividade de vocalização e a precipitação do período amostral $\left(r_{s}=0,19 ; p=0,53 ; n=13\right)$. Porém, a precipitação mensal foi significativamente correlacionada com a atividade de vocalização das espécies $\left(r_{s}=0,55 ; \mathrm{p}=0,05 ; \mathrm{n}=13\right)$. O número de espécies ativas em cada mês foi correlacionado com a umidade relativa do ar média mensal $\left(\mathrm{r}_{\mathrm{s}}=0,60 ; \mathrm{p}=0,02 ; \mathrm{n}=13\right)$ e marginalmente correlacionada com a umidade relativa do ar média durante o período amostral $\left(\mathrm{r}_{\mathrm{s}}=0,48 ; \mathrm{p}=0,09 ; \mathrm{n}=13\right)$. Houve correlação entre a temperatura média mensal e a 


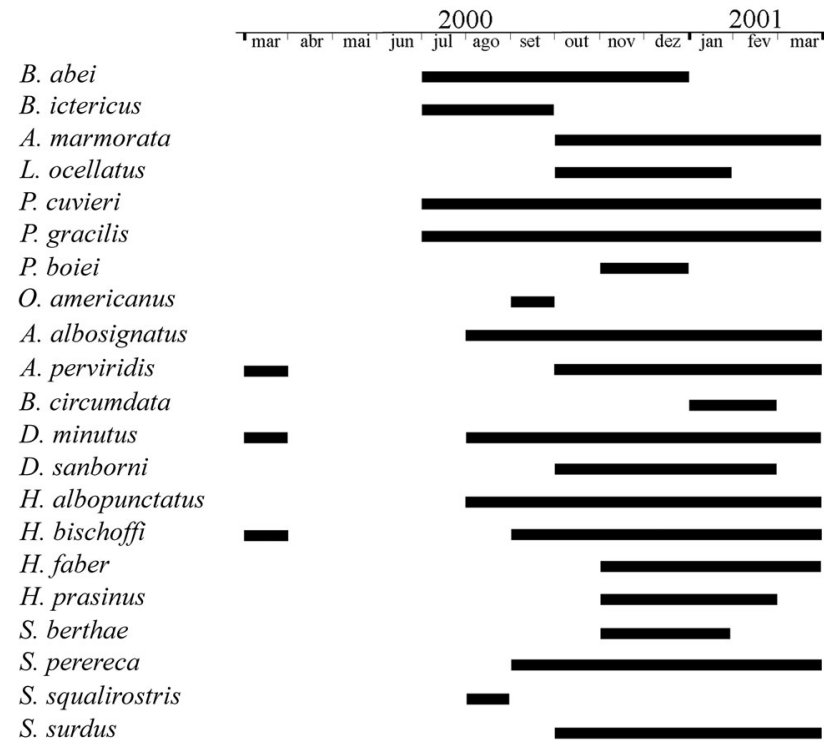

Figura 1. Ocorrência mensal de espécies em atividade de vocalização, no período de março de 2000 a março de 2001 no Município de Tijucas do Sul, Paraná.

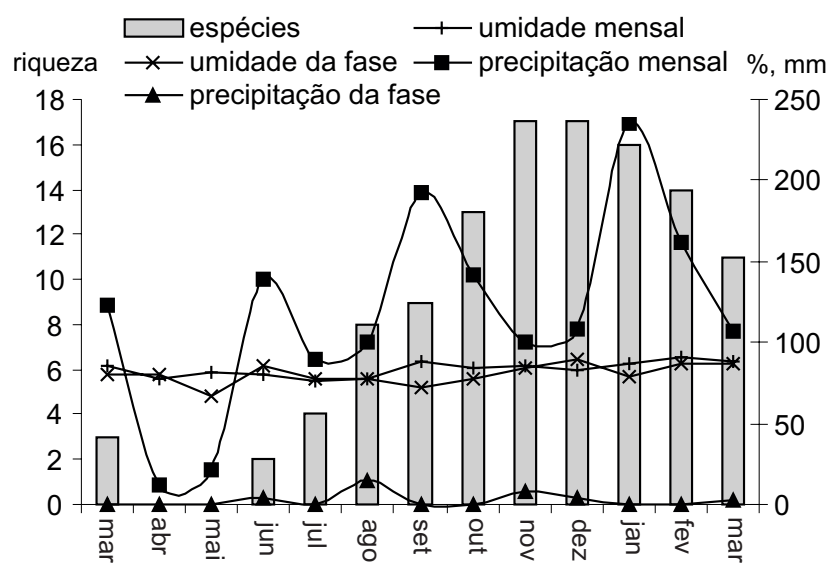

Figura 2. Relação entre o número de espécies em atividade de vocalização com a precipitação e umidade, divididas em média mensal e média da fase de campo, durante os meses de março de 2000 a março de 2001.

do período amostral com o número de espécies em atividade de vocalização $\left(\mathrm{r}_{\mathrm{s}}=0,61 ; \mathrm{p}=0,02 ; \mathrm{n}=13, \mathrm{r}_{\mathrm{s}}=0,70 ; \mathrm{p}=0,00 ; \mathrm{n}=13\right.$, respectivamente). As temperaturas máxima mensal e máxima do período amostral são correlacionadas com o número de espécies vocalizando $\left(r_{s}=0,71 ; p=0,00 ; n=13, r_{s}=0,64 ; p=0,01 ; n\right.$ $=13$, respectivamente). Também houve correlação entre número de espécies em atividade de vocalização com as temperaturas mínima mensal e mínima do período amostral $\left(\mathrm{r}_{\mathrm{s}}=0,63 ; \mathrm{p}=\right.$ 0,$01 ; n=13 ; r_{s}=0,69 ; p=0,00 ; n=13$, respectivamente).
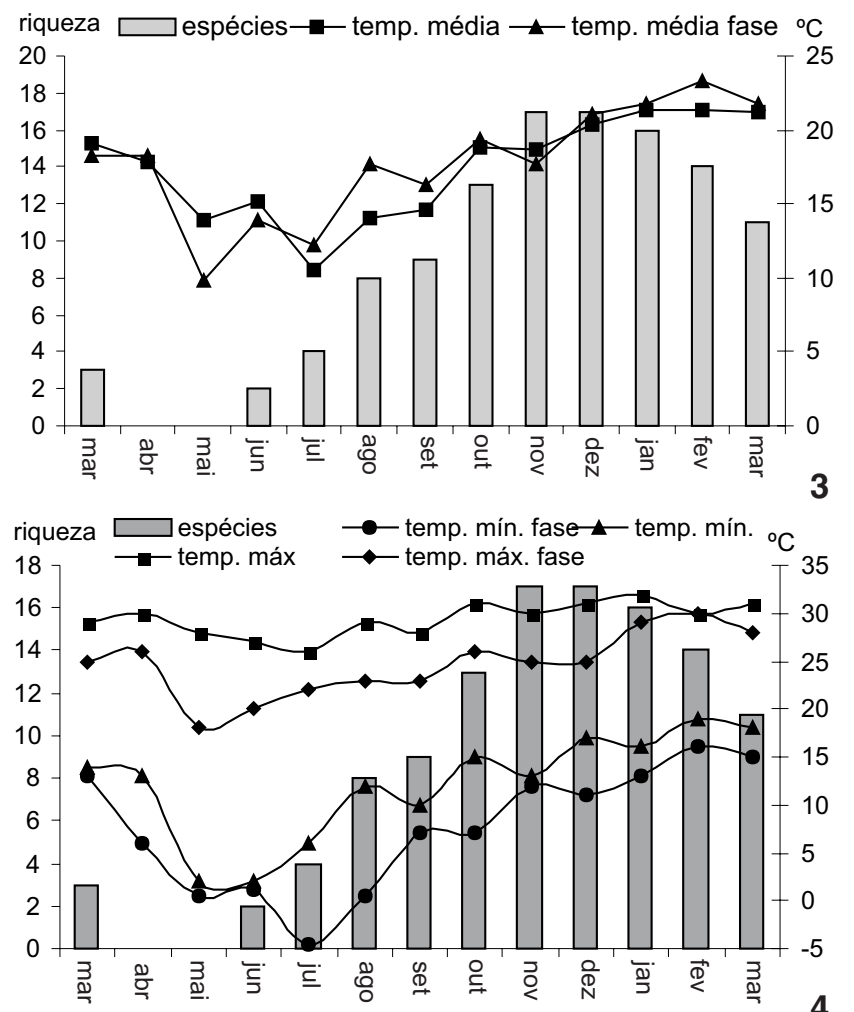

Figuras 3-4. Relação entre o número de espécies em atividade de vocalização com a temperatura média mensal (3) e temperatura máxima e mínima (4), divididas em média mensal e média do período amostral, durante os meses de março de 2000 a março de 2001.

\section{Uso dos habitats}

Onze espécies foram encontradas vocalizando em habitat fortemente impactado (A2), sugerindo um caráter eurióico. Cinco espécies foram encontradas vocalizando apenas na borda florestal e quatro espécies foram encontradas vocalizando somente no ribeirão no interior da floresta (Tab. I). Dendropsophus minutus, $H$. bischoffi e $S$. perereca foram consideradas neste estudo como espécies generalistas, pois foram encontradas vocalizando em áreas abertas, borda e interior de floresta (Tab. I). Os habitats com maior similaridade foram A2 e A3 $\left(C_{j}=62,5\right)$ (Fig. 5).

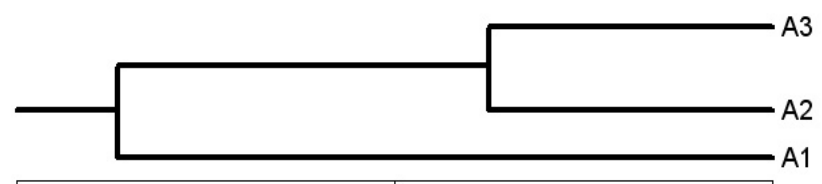

0, \% Similarity 50 , 100

Figura 5. Similaridade na composição da anurofauna dos habitats amostrados: interior de floresta, A1; borda florestal, A2 e área aberta, A3.

Revista Brasileira de Zoologia 22 (4): 940-948, dezembro 2005 


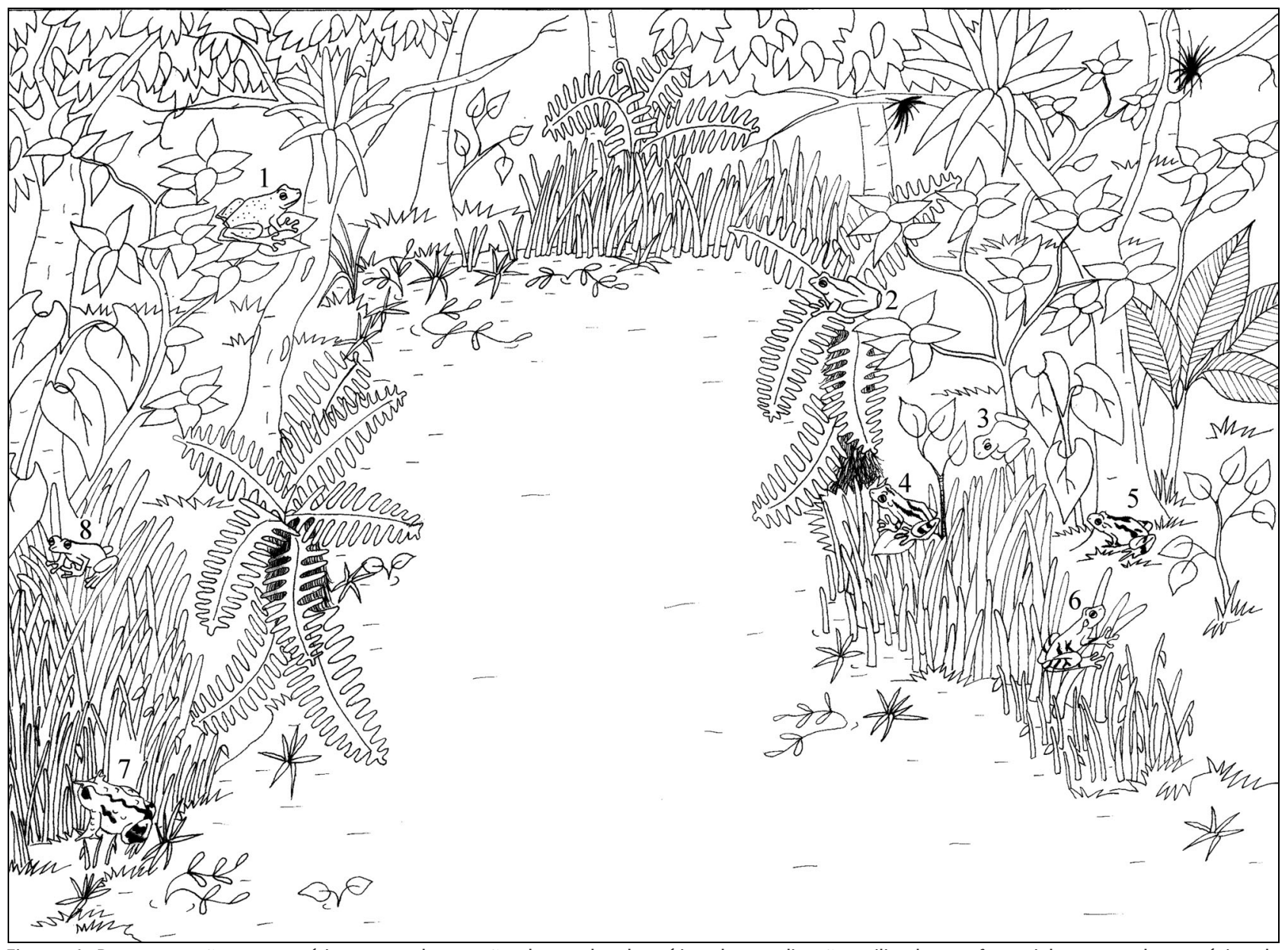

Figura 6. Representação esquemática, sem observação de escala, dos sítios de vocalização utilizados preferencialmente pelas espécies de anuros no habitat A1: 1) A. albosignatus; 2) H. bischoff; 3) S. perereca; 4) S. berthae; 5) A. marmorata; 6) B. circumdata; 7) P. boiei; 8) D. minutus.

\section{Utilização dos diferentes sítios de vocalização}

Área A1: foi o habitat que apresentou o menor número de espécies $(n=8)$ em atividade de vocalização (Tab. I, Fig. 6). Machos das espécies vocalizaram em diferentes sítios de vocalização:

Sobre o solo, em formações brejosas: P. boiei.

Empoleirados em vegetação herbácea emergentes e marginais: Scinax perereca e $H$. bischoffi $(5-100 \mathrm{~cm}$ de altura), $B$. circumdata $(50-70 \mathrm{~cm}$ de altura), $S$. berthae $(15-30 \mathrm{~cm}$ de altura) e Dendropsophus minutus que vocalizou sobre vegetação flutuante até $50 \mathrm{~cm}$ de altura.

Empoleirados em árvores e/ou arbustos ao redor do ribeirão: A. albosignatus (50-400 cm de altura).

Chão da floresta: distante dos corpos d'água: A. marmorata, sendo encontrados da borda para o interior do fragmento florestal, vocalizando diretamente na serapilheira ou empoleirados em vegetação herbácea até $10 \mathrm{~cm}$ de altura.

Área A2: este foi o habitat que apresentou o maior número de espécies $(n=16)$ em atividade de vocalização (Tab. I, Fig. 7).
No nível d'água: machos de $P$. gracilis, e $P$. cuvieri vocalizaram nas partes rasas do açude, em pequenas depressões parcialmente flutuando. Machos de B. ictericus, B. abei, L. ocellatus e O. americanus vocalizaram na margem do açude com ou sem vegetação rasteira, sobre o solo ou parcialmente submersos, nesse caso com os membros apoiados no fundo do açude ou em galhos.

Empoleirados em taboal no interior do açude: $H$. albopunctatus e $H$. prasinus $(5-40 \mathrm{~cm}$ de altura), D. sanborni $(50-75 \mathrm{~cm}$ de altura), $H$. faber até $30 \mathrm{~cm}$ de altura e $S$. surdus até $100 \mathrm{~cm}$ de altura.

Empoleirados em arbustos e herbáceas na margem do açude: Aplastodiscus perviridis (40-150 cm de altura), H. bischoffi e $S$. perereca (10-100 cm de altura) e D. minutus até $50 \mathrm{~cm}$ de altura.

Vegetação flutuante na altura da superfície d'água: $H$. faber, D. minutus e S. surdus.

Área A3: machos de 11 espécies foram encontrados em atividade de vocalização (Tab. I, Fig. 8) - as espécies apresenta- 


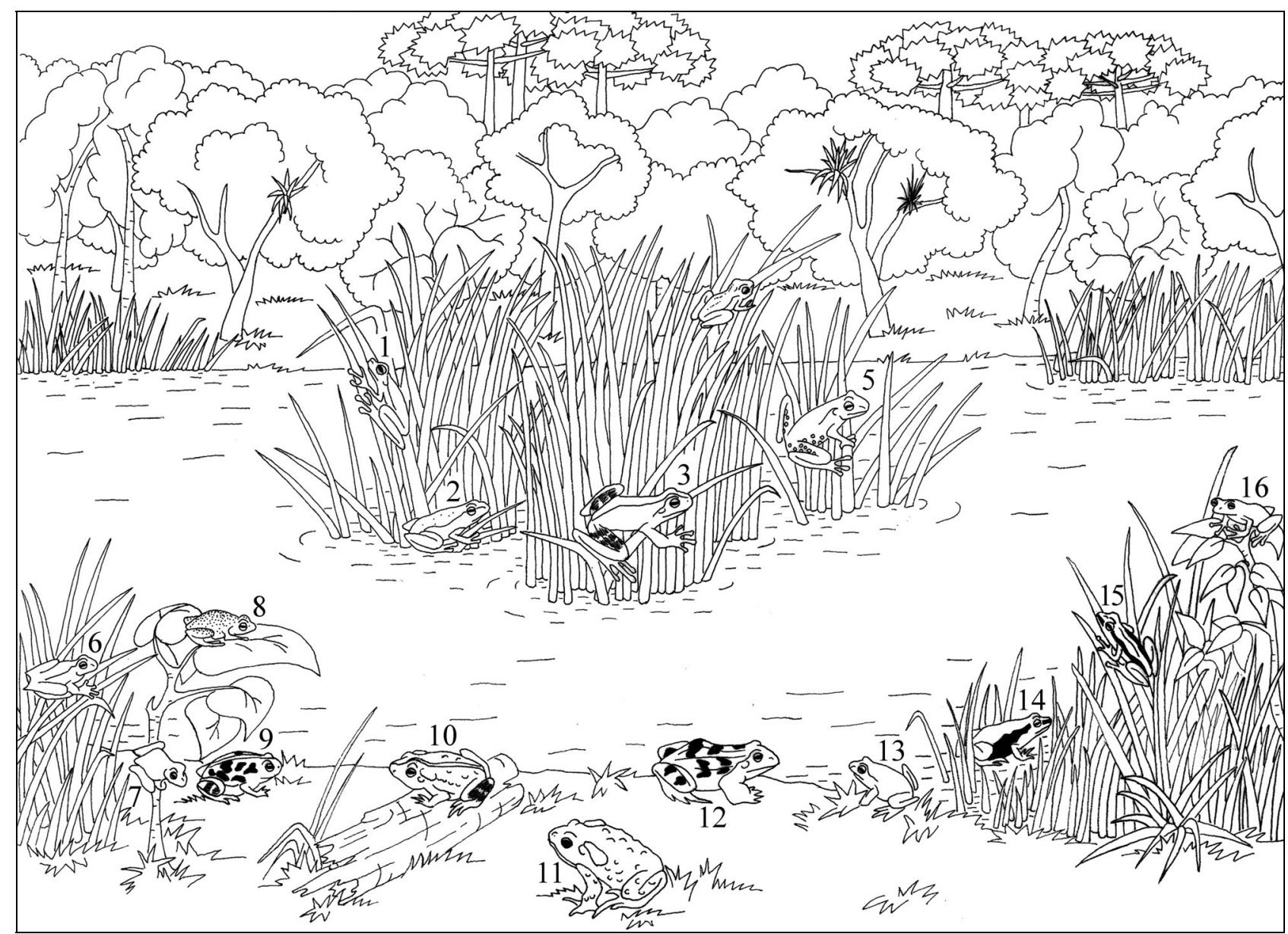

Figura 7. Representação esquemática, sem observação de escala, dos sítios de vocalização utilizados preferencialmente pelas espécies de anuros no habitat A2: 1) H. prasinus; 2) S. surdus; 3) H. faber; 4) D. sanborni; 5) H. albopunctatus; 6) H. bischoffi; 7) S. perereca; 8) A. perviridis; 9) O. americanus; 10) B. abei; 11) B. ictericus; 12) L. ocellatus; 13) P. cuvieri; 14) P. gracilis; 15) S. squalirostris; 16) D. minutus.

ram o mesmo comportamento no uso dos sítios de vocalização do habitat A2, diferindo apenas para os machos de $S$. surdus que foram encontrados vocalizando somente na superfície d'água, sobre vegetação emergente e machos de H. albopunctatus que, nos meses de dezembro e janeiro, quando o volume de machos foi superior a 40 indivíduos, foram encontrados vocalizando tanto empoleirados quanto diretamente sobre o solo, com ou sem vegetação rasteira.

\section{DISCUSSÃO}

O número de espécies registradas ( $\mathrm{n}=23$ ) representa 19\% daquelas conhecidas para o Estado do Paraná, que é de aproximadamente 120 spp. (Segala \& LANGONe 2004). A riqueza obtida está próxima àquelas registradas para outras localidades paranaenses, como o Parque Estadual Mata dos Godoy, Londrina ( $n=27$; o Parque Estadual do Rio Guarani, Três Barras do Paraná (n = 23); a Fazenda Santa Rita, Palmeira $(\mathrm{n}=19)$; e a
Chácara São Francisco de Assis e Morro Anhangava, Quatro Barras ( $\mathrm{n}=22$ ) (Bernarde \& Machado 2000). As espécies Cycloramphus bolitoglossus, Proceratophrys boiei e Sphaenorhynchus surdus foram exclusivas do presente estudo.

O período de atividade de vocalização da anurofauna local segue o padrão sazonal, no qual a maioria das espécies são encontradas em atividade de vocalização durante os meses mais quentes e chuvosos do ano. Este padrão também foi observado para anurofauna das regiões Sul (Bernarde \& Anjos 1999) e Sudeste do Brasil (Heyer et al. 1990, Rossa-Feres \& Jim 1994, Pombal JR. 1997, Bertoluci 1998, Bernarde \& Kokubum 1999), embora nem todos esses autores tenham testado a correlação entre as variáveis bióticas e abióticas. Dentre os estudos acima citados, apenas BERTOLUCI (1998) encontrou correlação entre o número de machos em atividade de vocalização com a temperatura média mensal, e Bernarde \& KoKubum (1999) entre número de espécies em atividade de vocalização com a pluviosidade. Se-

Revista Brasileira de Zoologia 22 (4): 940-948, dezembro 2005 


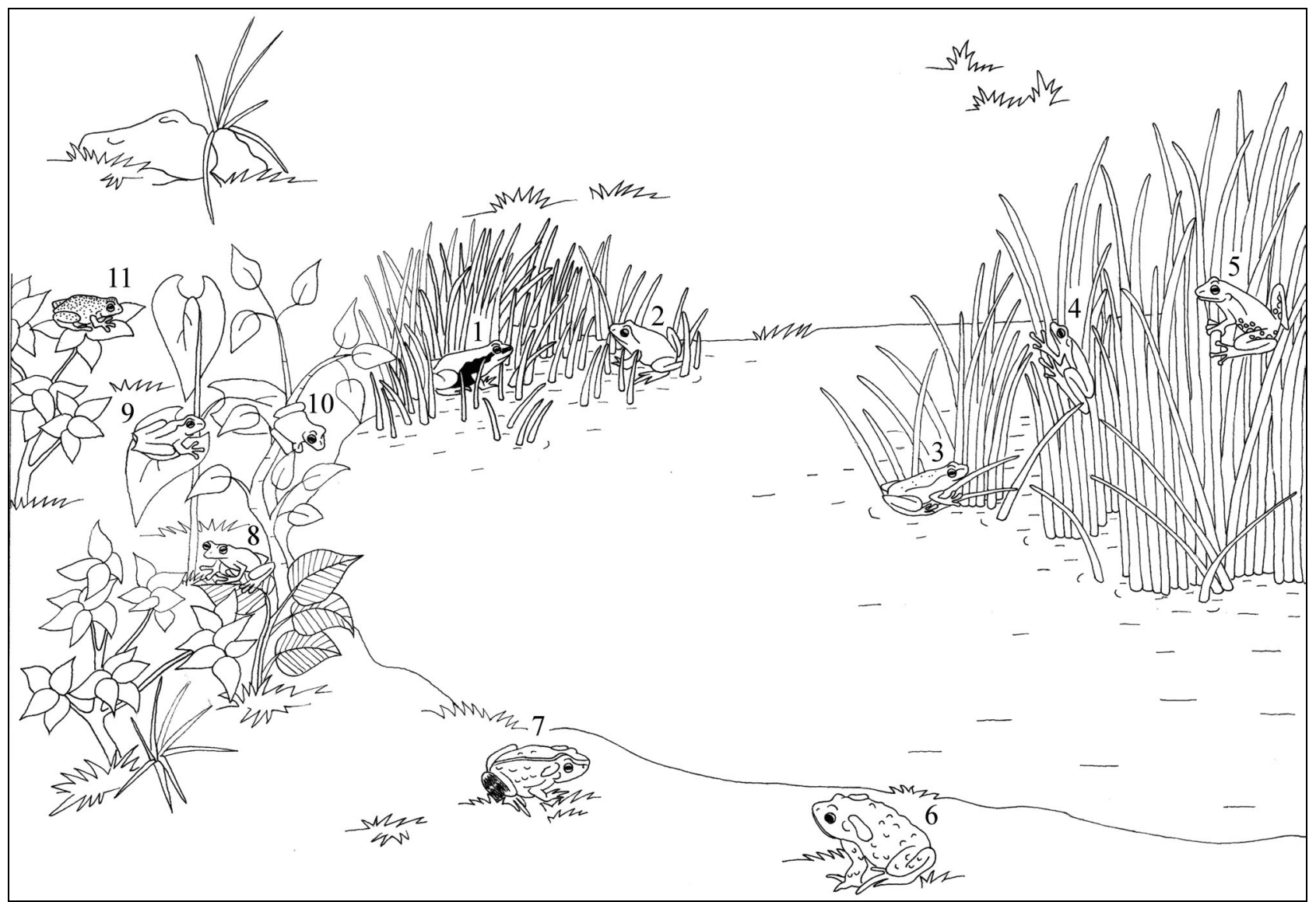

Figura 8. Representação esquemática, sem observação de escala, dos sítios de vocalização utilizados preferencialmente pelas espécies de anuros no habitat A3: 1) P. cuvieri; 2) P. gracilis; 3) S. surdus; 4) H. prasinus; 5) H. albopunctatus; 6) B. ictericus; 7) B. abei; 8) D. minutus; 9) $H$. bischoffi; 10) S. perereca; 11) A. perviridis.

gundo Pombal JR.(1997), a falta de correlação sugere a existência de um conjunto de fatores climáticos influenciando a atividade de vocalização.

As espécies apresentaram certa especificidade na utilização de habitats com características distintas (e.g. "espécies de interior de floresta" e "espécies de área aberta"), sendo que das 21 espécies observadas em atividade de vocalização, apenas três foram encontradas em todos os habitats estudados.

De modo geral, os sítios de vocalização foram idênticos aos registrados para as mesmas espécies em outras localidades, diferenciando para algumas apenas na altura máxima de empoleiramento (Bernarde \& Anjos 1999, Bernarde \& Machado 2000, Bertoluci \& Rodrigues 2002). Cabe destacar, porém, que uma mesma espécie pode se comportar de maneira diferente de uma região para outra (CARDOSo 1984).

No habitat de interior de floresta, as espécies apresentaram evidente segregação espacial, pois utilizaram sítios de vocalização específicos. Apesar dos machos de $H$. bischoffi e $S$. perereca utilizarem a mesma altura de empoleiramento, machos de
H. bischoffi vocalizaram mais expostos sobre as folhas ou galhos enquanto que os de $S$. perereca vocalizaram em substratos mais abrigados no meio da vegetação, entre folhas e galhos. Este comportamento também foi observado nos demais habitats.

Já nos habitats de área aberta e de borda florestal, algumas espécies apresentaram elevada sobreposição em relação ao sítio de vocalização (espacial e temporal). Machos de $H$. albopunctatus e $H$. prasinus e as espécies de Bufo utilizaram a mesma altura de empoleiramento e/ou os mesmos substratos. Já para os machos de Leptodactylus ocellatus e O. americanus que utilizaram os mesmos sítios de vocalização dos bufonídeos, a sobreposição temporal foi baixa.

As espécies do gênero Physalaemus apresentaram sobreposição parcial do sítio de vocalização; os machos de $P$. gracilis vocalizaram sob vegetação emergente ou em interior de touceiras enquanto os machos de $P$. cuvieri vocalizaram mais expostos.

Estudos em comunidades de anfíbios anuros têm constatado que o sítio de vocalização é um fator importante na segregação das espécies (CARDoso et al. 1989) e está relacionado pri- 
mariamente com a morfologia e tamanho de cada espécie (CRUmp 1971, HöDl 1977). No presente estudo, a maioria das espécies apresentaram segregação total ou parcial do sítio de vocalização. Entretanto, o maior número de espécies nos habitats de área aberta e/ou borda florestal foram responsáveis por elevada sobreposição do sítio de vocalização para algumas espécies ( $H$. albopunctatus e $H$. pasinus e as espécies de Bufo). De fato, em habitats de área aberta e/ou borda florestal o número de sítios de vocalização tende a ser menor que o número de espécies (CARDoso et al. 1989). Já em relação à distribuição temporal ocorreu sobreposição, a qual, de acordo com POMBAL JR. (1997), não parece ser um mecanismo importante de isolamento reprodutivo entre as espécies.

Segundo Bertoluci \& Rodrigues (2002), Sphaenorhynchus Tschudi, 1838 é um gênero que ilustra a fidelidade que algumas espécies apresentam por determinados sítios de vocalização. BOKERMANN (1966) usou como uma das justificativas para separação de Sphaenorhynchus em gênero próprio os hábitos aquáticos semelhantes a Pseusdis Wagler, 1830. Vocalização sobre vegetação flutuante foi observado para machos de $S$. carneus (Cope, 1868) e S. dorisae (Goin, 1957) na Amazônia (HöDl 1977) e para S. surdus em São Paulo (Pombal Jr.1997, Bertoluci \& RoDRIGUEs 2002). Entretanto, foi observada uma plasticidade em relação ao sítio de vocalização de $S$. surdus. Machos foram observados vocalizando tanto na altura d'água, apoiados em vegetação flutuante em posição horizontal, quanto em folhas de taboa até $100 \mathrm{~cm}$ de altura em posição vertical. O mesmo hábito de vocalizar empoleirado foi constatado por BoKERMANN (1973), que observou S. pauloalvini Bokermann, 1966 vocalizando entre 50 e $100 \mathrm{~cm}$ de altura em vegetação aquática e FEıo et al. (1998) que observaram machos de S. prasinus Bokermann, 1973 vocalizando sobre a vegetação flutuante ou empoleirados em arbustos próximos à margem de lagoas. Esses dados reforçam a plasticidade em relação ao sítio de vocalização para algumas espécies do gênero Sphaenorhynchus, que podem vocalizar tanto no nível d'água quanto empoleirados.

Apesar da maioria das espécies encontradas serem caracterizadas como eurióicas, 20\% das espécies da anurofauna local são tidas como estenóicas dependentes de habitats florestais. Considerando o lastimável cenário de destruição florestal do Estado do Paraná, ressalta-se a importância da preservação dos remanescentes florestais para conservação da anurofauna.

\section{AGRADECIMENTOS}

Somos gratos pelo auxílio no projeto ao Programa de Ação Comunitária e Ambiental - PUCPR; ao Peld CNPq - Ecossilvibras - Site 9, pelo auxílio financeiro; ao Sylvio Péllico Netto, Madalena T. Shirata, Janete L. Conci pelo apoio e credibilidade. Aos amigos e companheiros de campo: Janael Ricetti, Gledson V. Bianconi, Arthur A. B. de Oliveira, Fabiana R. Mendes, Rodrigo P. Di Napoli, Josiane S. Gruber e Aline Dal'Maso Ferreira. Ao José P. Pombal Jr., Paulo S. Bernarde e Gledson V. Bianconi pela leitura crítica do manuscrito. A Aline Dal'Maso Ferreira pelas ilustrações e Rodrigo Lingnau pela revisão do abstract. A Célio Baptista F. Haddad, Oswaldo L. Peixoto e Vanessa K. Verdade pela confirmação de algumas espécies. Ao Conselho Nacional de Desenvolvimento Científico e Tecnológico - CNPq pela concessão da bolsa de doutorado a R.A.M.

\section{RERERÊNCIAS BIBLIOGRÁFICAS}

BernaRde, P.S. 1998. Geographic distribution: H. punctata. Herpetological Review, Lawrence, 29 (4): 246.

BernaRde, P.S. 1999. Geographic distribution: H. uruguaya. Herpetological Review, Lawrence, 30 (4): 230.

BernaRde, P.S. \& L. ANJos. 1999. Distribuição espacial e temporal da anurofauna do Parque Estadual Mata dos Godoy, Londrina, Paraná, Brasil (Amphibia, Anura). Comunicações do Museu Ciências e Tecnologia da PUCRS, Série Zoologia, Porto Alegre, 12: 127-140.

Bernarde, P.S. \& M.N.C. KoKubum. 1999. Anurofauna do Município de Guararapes, Estado de São Paulo, Brasil (Amphibia, Anura). Acta Biologica Leopoldensia, São Leopoldo, 21: 89-97.

Bernarde, P.S. \& R.A. Machado. 2000. Riqueza de espécies, ambientes de reprodução e temporada de vocalização da anurofauna em Três Barras do Paraná, Brasil (Amphibia: Anura). Cuadernos de Herpetologia, Tucumán, 14 (2): 93-104.

Bertoluci, J. 1998. Annual patterns of breeding activity in Atlantic Rainforest anurans. Journal of Herpetology, Saint Louis, 32 (4): 607-611.

Bertoluci, J. \& M.T. Rodrigues. 2002. Utilização de habitats reprodutivos e micro-habitats de vocalização em uma taxocenose de anuros (Amphibia) da Mata Atlântica do sudeste do Brasil. Papéis Avulsos de Zoologia, São Paulo, 42 (11): 287-297.

Bokermann, W.C.A. 1966. Duas novas espécies de "Sphaenorhynchus" (Amphibia, Hylidae). Revistas Brasileira de Biologia, Rio de Janeiro, 26 (1): 15-21.

Bokermann, W.C.A. 1973. Duas novas espécies de "Sphaenorhynchus" da Bahia (Anura, Hylidae). Revista Brasileira de Biologia, Rio de Janeiro, 33 (4): 589-594.

Brewer, R. 1994. The Science of Ecology. Philadelphia, Saunders, 773p.

Cardoso, A.J. 1984. Interações sociais em anfíbios. Ciência e Cultura, São Paulo, 36: 36-42.

Cardoso, A.J. \& J. Vielliard. 1990. Vocalizações de anfíbios anuros de um ambiente aberto em Cruzeiro do Sul, Estado do Acre. Revista Brasileira de Biologia, Rio de Janeiro, 50 (1): 229242.

Cardoso, A.J.; G.V. Andrade \& C.F.B. Haddad. 1989. Distribuição espacial em comunidades de anfíbios (Anura) no Sudeste do Brasil. Revista Brasileira de Biologia, Rio de Janeiro, 49 (1): 241-249.

Castanho, L. \& C.F.B. Haddad. 2000. New species of Eleutherodactylus (Amphibia: Leptodactylidae) from Guaraqueçaba, Atlantic Forest of Brazil. Copeia, Lawrence, 33 (3): 777-781.

Conte, C.E.; R. Lingnau \& A. Kwet. 2005. Description of the advertisement call of Hyla ehrhardti, Müller, 1924 and new 
distribution records (Anura: Hylidae). Salamandra, Rheinbach, 41 (3): 147-151.

Crump, M.L. 1971. Quantitative analysis of the ecological distribition of a tropical herpetofauna. Occasional Papers of the Museum of Natural History of the University of Kansas, Lawrence, 3: 1-62.

DAJOz, R. 1972. Ecologia Geral. Petrópolis, Editora Vozes, Editora da Universidade de São Paulo, 174p.

Duellman, W.E. \& L. Trueb. 1986. Biology of Amphibians. New York, McGraw-Hill Book, 670p.

Ferreira, J.C.V. 1996. O Paraná e seus municípios. Cuiabá, Memória do Brasil, $2^{a}$ ed, 728p.

Feio, R.N.; U.M.L. Braga; H. Wiederhecker, \& P.S. Santos. 1998. Anfíbios do Parque Estadual do Rio Doce (Minas Gerais). Viçosa, Universidade Federal de Viçosa, Instituto Estadual de Florestas, 32p.

Heyer, W.R.; A.S. Rand; C.A.G. Cruz; O.L. Peixoto \& C.E. Nelson. 1990. Frogs of Boracéia. Arquivos de Zoologia, São Paulo, 31 (4): 231-410.

HöDL, W. 1977. Call differences and calling site segregation in anuran species from Central Amazonian floating meadows. Oecologia, Heidelberg, 28: 351-363.

KREBS, C.J. 1999. Ecological Methodology. Menlo Park, Addison Wesley Longman, 620p.

Langone, J.A. \& M.V. Segala. 1996. Una nueva especie de Eleutherodactylus del Estado de Paraná, Brasil (Amphibia, Anura, Leptodactylidae). Comunicaciones Zoologicas del Museo de Historia Natural de Montevideo, Montevideo, 12 (185): 1-8.

Liebsch. D. \& L.A. Acra. 2004. Riqueza de espécies de sub-bosque de um fragmento de floresta ombrófila mista em Tijucas do Sul, PR. Ciência Florestal, Santa Maria, 14 (1): 67-76.

Lingnau, R. 2000. Geographic distribution. Hylodes heyeri. Herpetological Review, Lawrence, 31 (3): 251.

MAACK, R. 1981. Geografia Física do Estado do Paraná. Rio de Janeiro, José Olympio Editora, 450p.

Machado, R.A; P.S. Bernarde; S.A.A. Morato; L. Anjos. 1999. Análise comparada da riqueza de anuros entre duas áreas com diferentes estados de conservação no Município de Londri- na, Paraná, Brasil (Amphibia, Anura). Revista Brasileira de Zoologia, Curitiba, 16 (4): 997-1004.

Machado, R.A. \& C.E. Conte. 2001. Geographic distribution. $H$. nahdereri. Herpetological Review, Lawrence, 32 (2): 114.

Machado, R.A. \& C.F.B. HADDAD. 2001. Geographic distribution. H. anceps. Herpetological Review, Lawrence, 32 (2): 113.

Paraná. 1987. Atlas do Estado do Paraná. Curitiba, Secretaria de Estado da Agricultura e do Abastecimento, Instituto de Terras, Cartografia e Florestas, XI+73p.

Pombal JR., J.P. 1997. Distribuição espacial e temporal de anuros (Amphibia) em uma poça permanente na Serra de Paranapiacaba, sudeste do Brasil. Revista Brasileira de Biologia, Rio de Janeiro, 57: 583-594.

Pombal JR. J.P.; E.M. Wistuba \& M. Bornschein. 1998. A new espécies of brachycephalid (Anura) from the Atlantic Rainforest of Brazil. Journal of Herpetology, Saint Louis, 32 (1): 70-74.

Ribeiro, L.F.; A.C.R. Alves; C.F.B. HadDAD \& S.F, ReIs. 2005. Two new species of Brachicephalus Günther, 1858 from the state of Paraná, Southern Brazil (Amphibia, Anuro, Brachycephalidae). Boletim do Museu Nacional, Rio de Janeiro, 519: 1-18.

Rossa-Feres, D.C. \& J. Jim. 1994. Distribuição sazonal em comunidade de anfíbios anuros na região de Botucatu, São Paulo. Revista Brasileira de Biologia, Rio de Janeiro, 54 (2): 323334.

Segalla, M.V. \& J.A. Langone,. 2004. Anfíbios, p. 537-577. In: S.B. МıкICH \& R.S. BÉRNILS (Eds). Livro vermelho da fauna ameaçada no Estado do Paraná. Curitiba, Instituto Ambiental do Paraná, XVI+764p.

Sos-Mata AtlÂntica; InPE; Isa, 1998. Evolução dos remanescentes florestais e ecossistemas associados do domínio da Mata Atlântica no período de 1990-1995. São Paulo, Fundação SOS Mata Atlântica, Instituto Nacional de Pesquisas Espaciais e Instituto Sócio-Ambiental, 47p.

Veloso, H.P.; A.L.R. Rangel-Filho \& J.C.A. Lima. 1991. Classificação da vegetação brasileira, adaptada a um sistema universal. Rio de Janeiro, IBGE, Departamento de Recursos Naturais e Estudos Ambientais, 124p.

Zar, J.H. 1984. Bioestatistical Analysis. New Jersey, Prentice Hall Internacional, $2^{\text {nd }}$ ed., $718 p$.

Recebido em 06.V.2005; aceito em 15.X.2005. 